\title{
Diretrizes para digitalizar e conservar os suportes de som
}

Marcelo Scarabuci

\author{
Graduado em Biblioteconomia pela Universidade \\ de Brasília
}

Ivette Kafure

\begin{abstract}
Professora Adjunta do Departamento de Ciência da Informação e Documentação da Universidade de Brasília
\end{abstract}

Esta pesquisa pretende justificar e dar início à concepção de uma metodologia de conservação e digitalização de suportes de som, por meio da união dos conhecimentos dos colecionadores, especialistas, instituições, manuais, guias internacionais e segmentos nacionais envolvidos.

Palavras-chave: Conservação; Preservação; Digitalização; Suportes Sonoros; Documentos Sonoros; Multimeios Sonoros.

\section{Guidelines of digitisation and conservation of sound supports}

This research aims to justify and start a methodology for sound conservation and sound recordings digitization by gathering the expertise of collectors, experts, institutions, manuals, international guides and national segments involved.

Keywords: Conservation; Preservation; Digitisation; Sound Supports; Sound Documents; Sound Multimedia.

\section{Introdução}

A tradução da vibração das ondas sonoras antecede o início da fabricação dos suportes sonoros, quando o inglês Thomas Young desenvolveu um aparelho que traduz de maneira gráfica as vibrações do corpo vibrante no começo do século XVIII (PICCINO, 2008). O suporte de som pode ser definido como a parte visível ou manipulável do documento sonoro propriamente dito (SIMEÃO; MIRANDA, 2002). Sua concepção é cercada de lendas e existem até algumas brigas pela paternidade da ideia, 
mas o fato é que Thomas Edison foi quem primeiro patenteou o fonógrafo e deu o grande passo para a popularização do suporte de som, ao descobrir que a vibração sonora poderia ser gravada. "Antes mesmo de captar a luz, Edison captara o eco" (LAMURE, 1935, p. 80).

De início, Edison custou a compreender o incalculável valor do fonógrafo para a reprodução de sons, tanto que o aparelho só foi publicamente apresentado em 1888 (onze anos depois de ter sido patenteado). Ainda no fim do século XIX, poucos documentos haviam sido gravados. O aparelho ainda tinha uma definição ruim, portanto Edison mantinha apenas uma coleção de vozes ilustres (inclusive uma poesia do Dalai Lama).

Mais tarde, os rolos de cera foram produzidos juntamente com os discos até a década de 20. Menos práticos e com menor espaço de gravação, os rolos deixaram de ser produzidos e o disco chato de 78Rpm, seu rival mercadológico, ganhou gravação nas duas faces.

Neste momento, também surgiam as fitas magnéticas, que só foram se popularizar alguns anos depois. Seu método de gravação e reprodução manteve praticamente os mesmos princípios.

A grande mudança seguinte ocorreu durante a Segunda Guerra, mas os discos de 33Rpm só se popularizaram na década de 50. Eram da mesma dimensão do antigo disco de 78Rpm (dez polegadas), porém em baixa rotação e com uma tecnologia diferente, ele suportava mais de oito minutos de gravação, enquanto o antigo apenas três minutos.

Em meados dos anos 60, os discos de 78Rpm definitivamente deixaram de ser fabricados, dando lugar aos populares LPs (Long Playing), que tinham doze polegadas de diâmetro e gravavam aproximadamente dezoito minutos em cada lado.

O CD surgiu para dinamizar ainda mais o mercado. Era um produto barato de se produzir e gravar, as músicas eram codificadas em células digitais da superfície de alumínio e jamais perderiam sua qualidade ou apresentariam chiados. Ou este funcionava bem, ou não funcionava. No Brasil, acabou-se por sepultar o disco de vinil, em 1996. Já no mercado internacional, o disco estava vivíssimo e nunca deixou de ser produzido.

Há, entretanto, a volta do vinil produzido no Brasil. A Polysom (última fábrica de vinil da América Latina) foi comprada pela Gravadora Deckdisc e já voltou a lançar vinis novos.

Não cabe abordar o tratamento com rolos, papéis e discos com gravações mecânicas (como as de caixas de música ou pianolas), pois são suportes de codificação, e funcionam apenas de guia para o equipamento. Assemelham-se a partituras, impossibilitando assim a digitalização de seu som. Também não serão abordados na digitalização arquivos lançados virtualmente, como os CDs que são também disponibilizados legalmente pela internet, pois o som já é digitalizado em alta qualidade e não há dependência direta de um suporte físico.

A conservação, portanto, referir-se-á ao manuseio, à limpeza e à guarda adequada deste material. Prever uma solução definitiva para a veloz degradação desses suportes é algo ainda utópico, porque, apesar de haver parâmetros de digitalização e de conservação bastante 
diversificados, ainda não é possível estabelecer parâmetros-base. Possivelmente, a união dos saberes de colecionadores, de profissionais e de instituições resultará em um melhor aproveitamento desta gama de conhecimentos tácitos e explícitos acerca do assunto.

\section{Suportes de som}

A International Association of Sound and Audiovisual Archives (IASA), em sua publicação "Cataloguing Rules" (1999), define um registro sonoro como "o produto do ato de registrar um evento específico em um formato de registro sonoro (por exemplo: disco, fita)", o que não é tão esclarecedor.

Primeiro, cabe definir o que é gravável, e por que essa gravação se torna um documento.

O som é definido como uma propagação de ondas no ar; sua vibração é captada pelos tímpanos e codificada pelo cérebro. Assim se faz a disseminação das ondas sonoras para o ouvido humano; estas ondas vibrantes podem ser gravadas.

Um documento sonoro se define pelo fato do som ter sido codificado e gravado para que outras pessoas pudessem escutá-lo novamente. Esse som, então gravado, torna-se um documento para ser re-consultado e reavaliado diversas vezes.

O que será gravado depende unicamente do usuário do sistema de gravação e do seu objetivo final. Existem, por exemplo, desde efeitos sonoros para mixagem com outras músicas ou interatividade com audiovisuais, até batidas de coração, para referência médica.

O universo do som é extremamente abrangente. Como bem apontou Mey (1999), a característica mais interessante destes suportes de som reside na possibilidade de seu uso por um público muito maior do que os registros impressos; afinal, o usuário de registros sonoros pode ser iletrado, pode pertencer a uma sociedade ágrafa, pode apresentar deficiências visuais e desconhecer por completo qualquer característica física e intelectual do registro e, mesmo assim, apreciá-lo.

Neste contexto, o documento sonoro será qualquer gravação sonora fidedigna advinda de um suporte físico.

\section{Degradação dos suportes de som}

A degradação de suportes de som é um fato primordial, já que a integridade da informação está ligada diretamente à conservação física do suporte. Portanto, se esta etapa não está sendo feita com coerência, pouco valerá uma segunda etapa, pois se tornará um serviço extremamente complexo.

Serra (2002) explica que o armazenamento digital ótico só é possível em CD, e a gravação analógica mecânica só é possível em vinil. Já a fita magnética aparece como um suporte híbrido, aceitando tanto a gravação digital quanto a analógica. Sendo assim, devemos observar as particularidades de degradação de cada suporte. 
Os CDs são sensíveis à luz forte, já que a informação contida neles provém de queimaduras por laser. Por outro lado, é imune a fontes magnéticas comuns. Os discos de vinil não são sensíveis à luminosidade nem a campos magnéticos, sua forma de gravação é algo puramente físico, de contato da agulha com ondulações. As fitas magnéticas, por sua vez, independente de serem gravadas digital ou analogicamente, são sensíveis a fontes magnéticas, como ímãs, que podem desalinhar suas informações.

À medida que os suportes de som evoluíram, a questão da sua conservação foi se complicando, com o surgimento de modelos com diversas especificações físico-químicas, criados com o objetivo de baratear a produção. Hoje, portanto, existem vários tipos de suportes de som, cada um com pontos fortes e fracos quando se trata da conservação, inclusive pelo modo de gravação, estando todos eles sujeitos à destruição iminente pelo tempo.

Aqueles que resistiram melhor ao tempo podem estar já obsoletos, fator este que não é correspondente à resistência do suporte. Mesmo o avançado $C D$ não pode ser considerado um suporte forte e confiável, uma vez que necessita de cuidados tanto quanto um centenário cilindro de Edison, por exemplo.

Segundo a pesquisa feita por Innarelli (2007), os fabricantes de CDs e derivados garantem uma segurança de dados por até cinco anos, em média. Após esse tempo, os CDs se tornam suportes absolutamente instáveis, sendo um descuido luminoso ou físico já suficiente para provocar fraturas irreversíveis nas células óticas.

A conservação está direcionada para todos os documentos, independente da idade. Raros são aqueles que resistem ao tempo em condições precárias. Alguns suportes, porém, merecem atenção especial, por sua composição e pela dificuldade de recuperação. Os discos virgens da década de 1950, por exemplo, têm uma composição física diferente dos discos convencionais. São constituídos por uma base de metal normalmente alumínio - que é coberta por um tipo de goma plástica. Com o tempo, esse plástico se contrai e se parte em centenas de pedaços, provavelmente devido às mudanças climáticas (de umidade e temperatura).

Como é possível ver na FIG. 1, em 1990 eles já eram considerados documentos perdidos; entretanto, é interessante notar o quanto progrediu a sua degradação em apenas onze anos. 

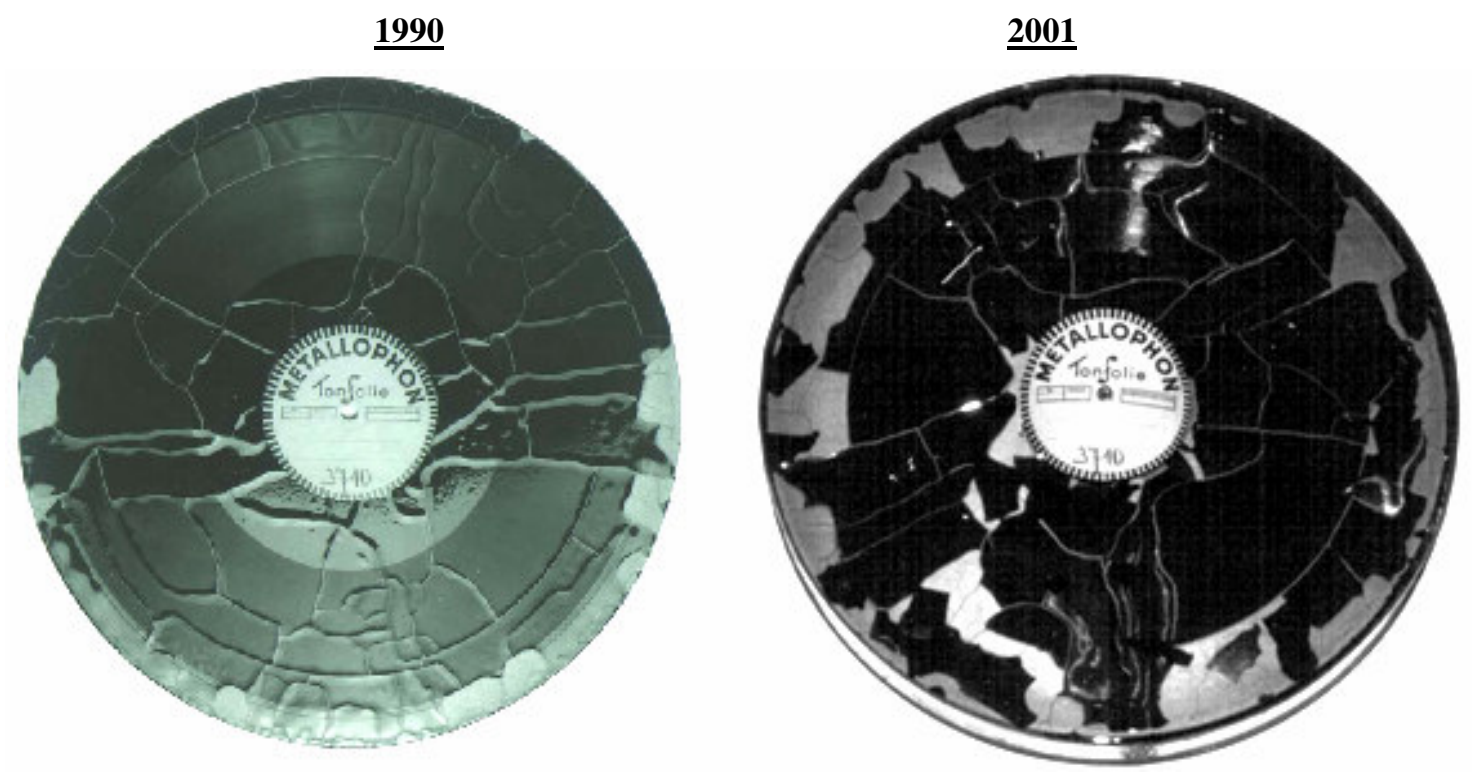

FIGURA 1 - Dois momentos de um disco especial da década de 1950

Fonte: Organização Das Nações Unidas (UNESCO), 2005.

A fita de rolo - outro "material especial" - era destinada principalmente a estúdios, para nela se fazer a gravação inicial, em que se podia errar, voltar e gravar por cima do erro antes de passar o som gravado para as matrizes que confeccionavam os discos. Também era utilizada para gravações caseiras, em ambientes que não dispunham de aparato para um estúdio, ou apenas para divertimento.

Para se ouvir o som gravado, a fita tem de ser desenrolada e, ao passar pelas cabeças de leitura, a sua estrutura é levemente dobrada. Se este suporte não tiver sido adequadamente armazenado e tratado, as pequenas curvas do trajeto são suficientes para "quebrar" o pigmento aglutinante na superfície do plástico-base, fazendo com que ele se perca. Na FIG. 2 é possível observar uma fita de rolo degradada pela hidrólise e que é destruída ao ser executada pelo tocador. 


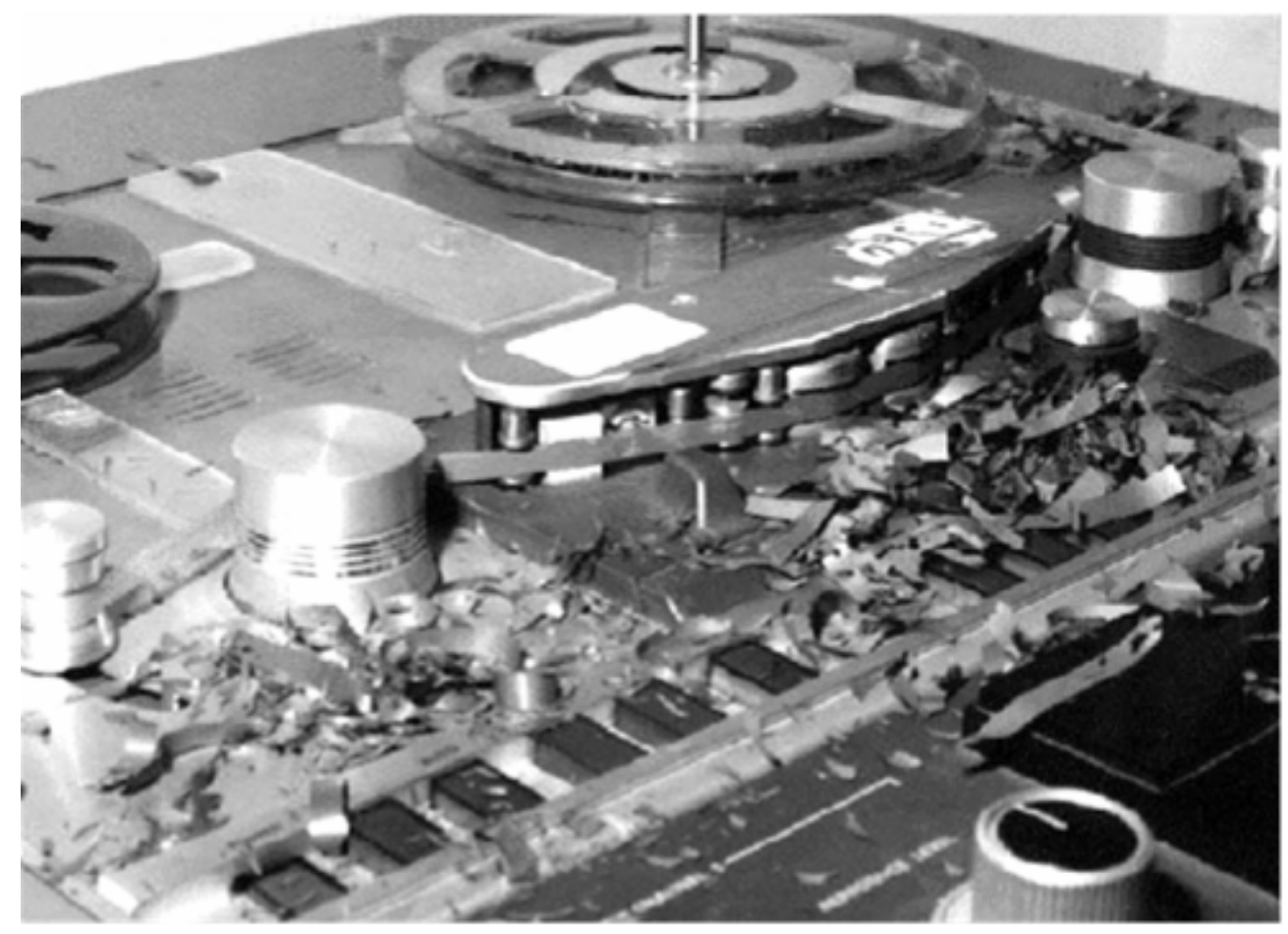

FIGURA 2 - Fita de rolo destruída pela hidrólise.

Fonte: UNESCO, 2005.

É fato que as condições naturais do ambiente colaboram para a degradação da superfície informacional dos discos e das fitas, mas também a ação humana, mediante o manuseio excessivo e/ou inadequado, contribui fortemente para esse processo.

Por se tratar de documentos únicos, é arriscado deixá-los com livre acesso nos acervos das instituições; por outro lado, é obrigação dos profissionais da informação suprir a necessidade de conhecimento dos mais jovens e dos pesquisadores quanto a este tipo de documento.

\section{Digitalização e conservação}

A preservação de conteúdo informacional deve atentar principalmente para o manuseio na conservação de mídias. Embora a digitalização por si só não constitua preservação, a conservação de materiais pelo formato digital é parte do processo de seleção para a preservação digital (COSTA E LIMA, 2007). A digitalização pode ser feita de várias maneiras, pois existem diferentes softwares e hardwares que garantem, dentro de suas limitações, o sucesso da gravação e a consequente conservação do registro original. É um processo demorado e que exige cuidados para se prolongar o tempo de vida do som migrado para um novo suporte; já que o original não precisará ser acessado e tocado todas as vezes que houver necessidade do documento sonoro, uma vez que "apenas a esfera digital oferece a possibilidade de diversas cópias fidedignas (sem perda de qualidade) quando se grava ou migra um documento sonoro" (IASA, 2005). 
A digitalização, ao contrário do que algumas pessoas pensam, não vai dispensar a necessidade dos originais. Um documento virtualizado pode ser facilmente alterado e modificado, portanto a garantia da veracidade e da legalidade desses arquivos virtualizados está justamente no documento original, que, praticamente, é impossível de ser alterado.

No universo da conservação ou da digitalização, o colecionador, o pesquisador e a instituição precisam compartilhar conhecimentos, pois, como ressalta o Comitê Técnico da IASA, a troca de informações fortalece e incentiva a criação de novos conhecimentos na área.

\subsection{Digitalização de suportes de som}

A digitalização dos suportes de som é um processo que demanda tempo e paciência. Digitalizar um vinil comum ou uma fita de uma hora pode levar de uma hora e meia a duas horas, dependendo do estado de conservação dos suportes e de como será feita a digitalização.

Há também que se atender à complexidade do arquivo. Como diz Serra (2002), não é necessário utilizar grandes frequências ao se gravar a voz, por exemplo, pois a amplitude da frequência para que a voz humana seja perfeitamente compreensível é entre $300 \mathrm{~Hz}$ e $3 \mathrm{KHz}$. Não é necessário, portanto, trabalhar as frequências existentes acima ou abaixo desta faixa. Dessa maneira, se faz uma boa economia de tamanho de arquivo ao digitalizá-lo. Já para uma orquestra, em que há timbres e frequências diversas, é necessária uma amplitude maior de frequência.

Não existe um consenso sobre o software a utilizar. Os mais populares atualmente são o Audacity ${ }^{*}$, que é um software aberto, grátis, e o Sound Forge, que é uma opção paga, da Sony.

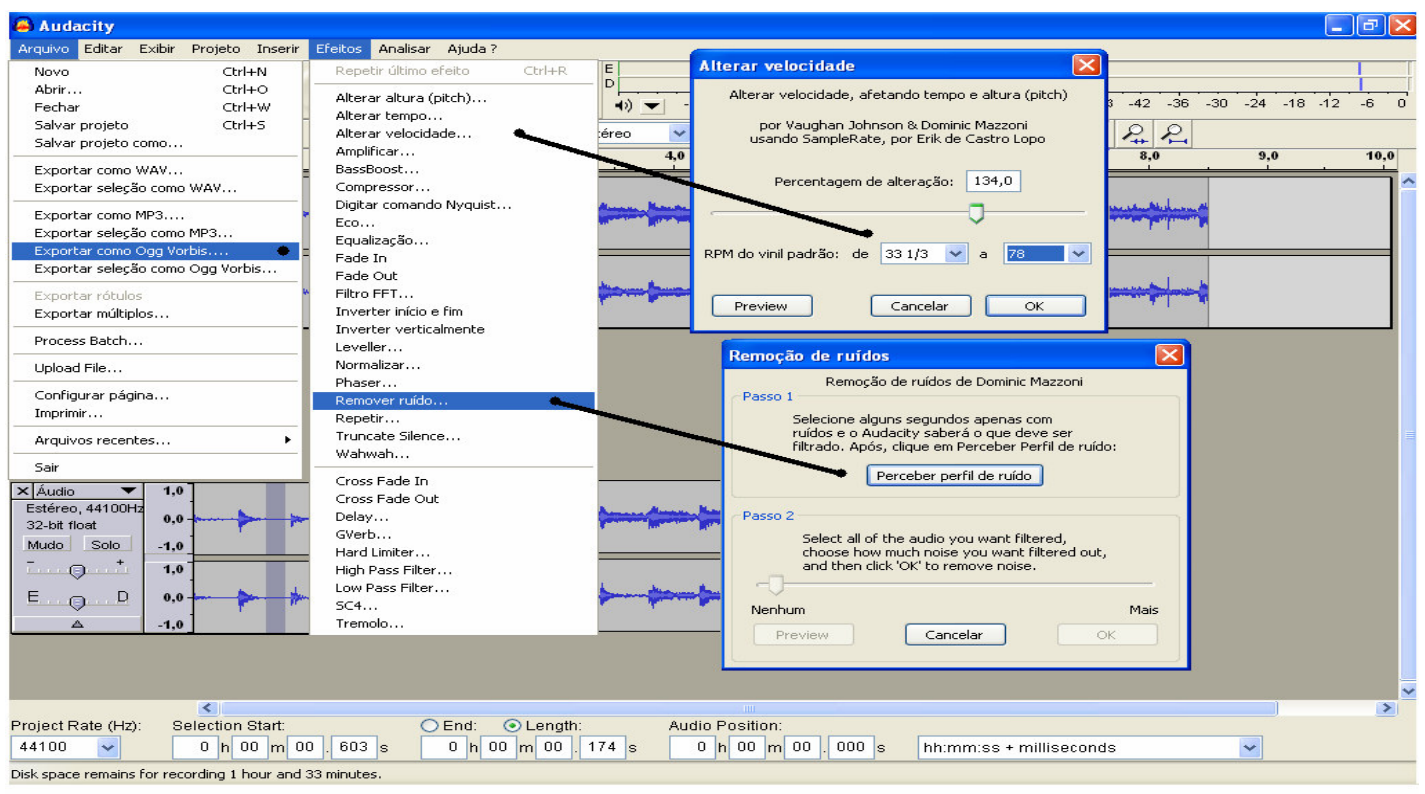

FIGURA 3 - Opções para interface do Audacity

\footnotetext{
A identificação do nome dos softwares e a apresentação de imagens mostrando suas características têm o objetivo de ilustrar o estudo realizado. Inclusive, podem ter sido modificados ou substituídos por novas versões nas entidades que os criaram.
} 
O Audacity é um software livre disponível em português, que permite, dentre outras opções, trabalhar com discos de vinil e fitas de diversas rotações. A opção 'modificar a velocidade do som' permite gravar um disco em rotação mais baixa do que a estipulada, podendo facilitar a sua visualização, sendo que, após o tratamento, pode-se colocar o som em sua velocidade original.

A opção de remover ruído também é de suma importância para o tratamento dos documentos sonoros, permitindo que o ruído do atrito do disco com a agulha, ou mesmo os sons do ambiente, da gravação original, sejam minimizados ou até eliminados.

A vantagem principal do Audacity, em termos de funcionalidade, é permitir a manipulação de diferentes faixas ao mesmo tempo (recurso de multipista), o que inclusive outros softwares menos populares (Sonar e Audition) possibilitam.

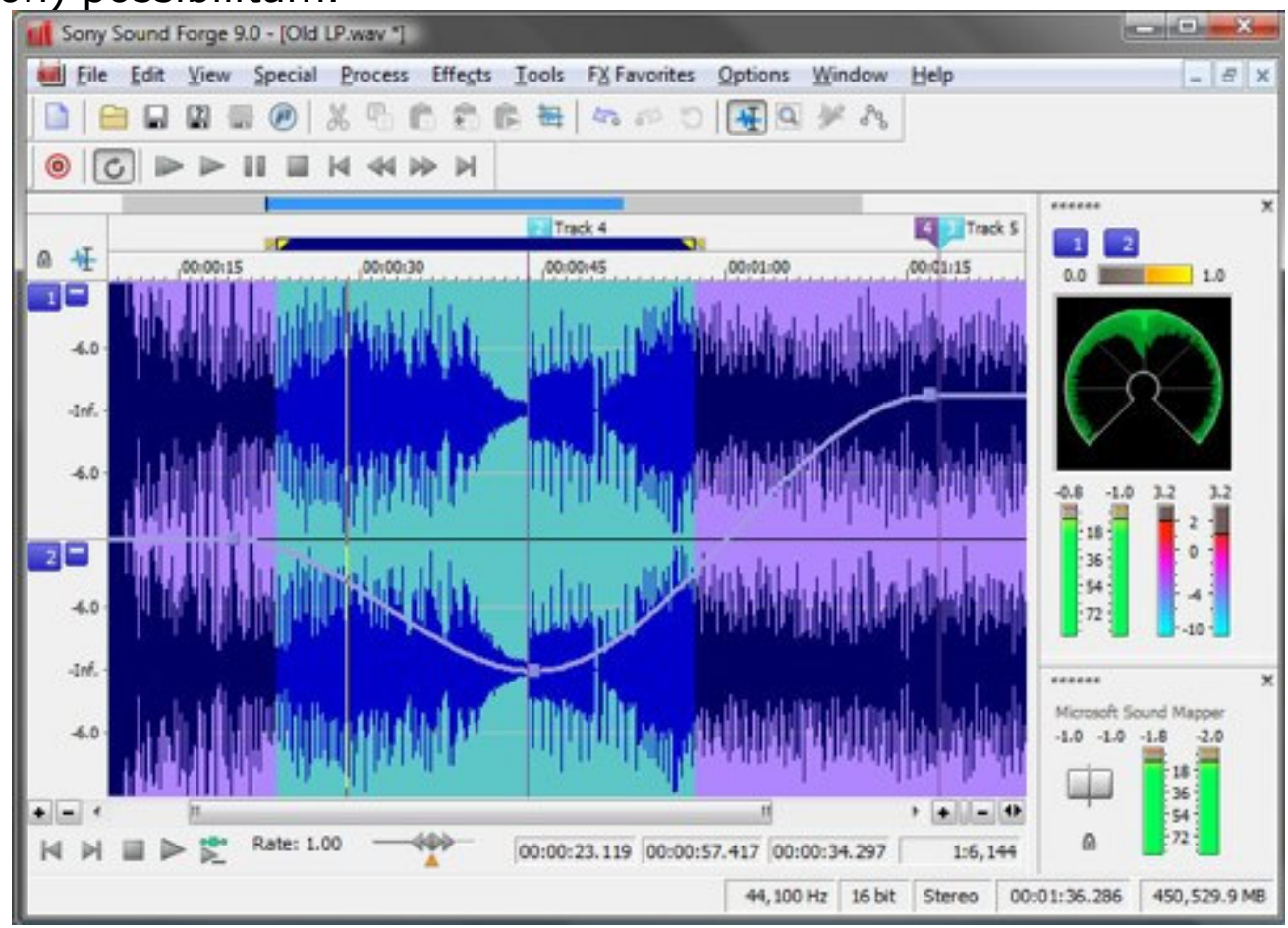

FIGURA 4 - Interface do Sound Forge 9.0

O Sound Forge, por sua vez, está disponível apenas em inglês e é um software pago. Suas funções são bastante similares às do Audacity, porém ele é muito mais interativo quando usado com outros aplicativos da Sony (como o editor de vídeo Vegas). Por não possuir o recurso Multipista, o usuário fica restrito aos dois canais convencionais do som estéreo ou a um do mono.

Contudo, qualquer som merece um tratamento adequado a seu fim, para que seja possível detalhar o som posteriormente, para recuperação ou regravação. Caso o trabalho fique incompleto, ou seja feito com baixa qualidade, o documento e sua utilidade serão limitados, e a gravação terá de ser refeita posteriormente.

Existem também tocadores a laser, capazes de ler discos e fitas, inclusive se avariados. Os discos, porém, são favorecidos por esta 
tecnologia (Laser Turntable), uma vez que, devido à angulação do laser, a leitura é feita em pontos jamais tocados pela agulha de audição convencional, como pode ser visto na FIG 5.

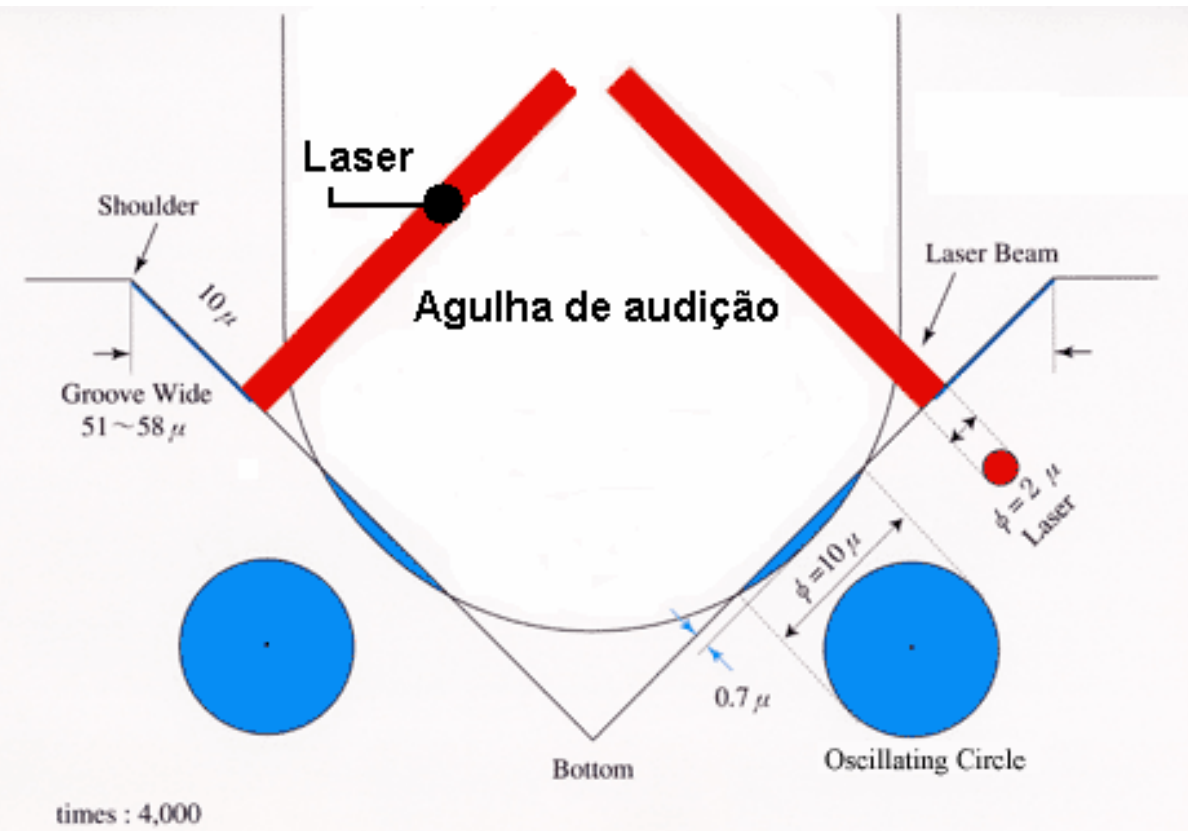

FIGURA 5 - Leitora de vinil a laser

Fonte: Elp Corporation, 2003.

Um consenso entre os que trabalham com digitalização é o modo de conectar os equipamentos. Uma sugestão bem plausível é colocar os equipamentos (computador e tocadores de som) em aparadores separados, para que as vibrações de um não sejam repassadas ao outro (FIG. 6). Além disso, os cabos utilizados devem ser blindados e curtos, a fim de evitar interferência e ruídos no trajeto do som até o computador.

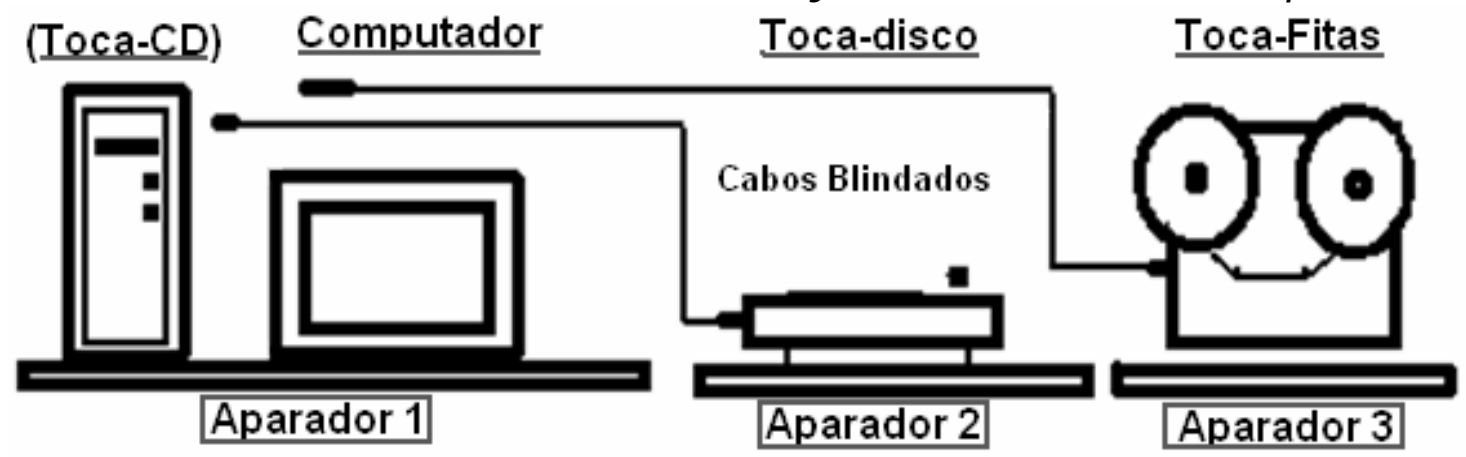

FIGURA 6 - Conexão dos hardwares para a digitalização 


\subsection{Conservação de suportes de som}

Quando se fala em conservação, estão implícitos os conceitos de manuseio, limpeza e guarda adequada dos suportes de som. Apesar do conhecimento tácito adquirido pelos colecionadores e pesquisadores parecer superficial, existem pontos muito avançados que precisam ser mesclados em prol da ideia de conservação.

\subsubsection{Manuseio}

A utilização de proteção nas mãos parece ser um ponto muito claro para todos. Não precisa ser feita com material descartável, basta apenas que impeça o contato da oleosidade da pele com a superfície do suporte que guarda a informação, e também com a capa do suporte, que identifica o documento.

\subsubsection{Limpeza}

Um ponto não divergente, mas amplo, é a limpeza física dos suportes. E de conhecimento de pesquisadores e colecionadores, e consta nos manuais de instituições, que não se devem utilizar abrasivos nem qualquer substância que possa atacar o suporte ou precipitar sua degeneração.

Definir uma mistura química permanente para a finalidade de limpeza pode ser uma grande utopia. Existem dezenas de soluções químicas para se fazer a limpeza, e a grande maioria é apropriada, justamente por não utilizarem abrasivos e sais. O tecido ideal para se aplicar a solução de limpeza ao disco é aquele que não solta fibras, sendo indicado o algodão hidrófilo, encontrado em farmácias.

Seguindo essa regra geral, para os discos de vinil e acetato pode ser feita uma solução caseira ou, simplesmente, pode-se comprar no mercado um xampu para bebês. Não há porque condenar soluções simples, baratas e práticas.

Quanto ao procedimento para se retirar a poeira do corpo da fita, St. Laurent (2001) sugere um aspirador de pó, mantendo-se o motor distante para evitar a desmagnetização. Porém, não se sabe até que ponto testar este procedimento seja uma boa ideia, pois o perigo está na possibilidade de o aspirador puxar e engolir ou danificar a fita. Para a limpeza das fitas, a proposta é de se usar um tecido especial, o tape cleaning fabric.

\subsubsection{Acomodação}

O processo de armazenamento também tem vários pontos em comum. Primeiramente, deve-se lembrar que a grande maioria das capas de discos é feita de papelão, um material extremamente ácido que, ao se desintegrar, solta pequenos fragmentos que entram nos sulcos dos discos. 
Apesar de dar um ar de originalidade aos discos de acetato, é necessário um plástico para protegê-los desses fragmentos e de outras sujidades.

As prateleiras devem estar sempre limpas. Quando as prateleiras são de vidro, a manutenção da limpeza é muito mais fácil; porém, devido ao peso excessivo do vinil, o vidro tem que ser grosso para garantir segurança ao usuário e aos discos, e o espaço na prateleira tem que ser curto (em torno de $20 \mathrm{~cm}$ ), para evitar que os discos exerçam pressão sobre os que estão na extremidade.

A fita magnética, por sua vez, não é de grande preferência da maioria dos colecionadores. Existe conhecimento sobre ela, mas pouco uso por parte deles, assim como nas instituições.

\section{Considerações finais}

Os principais problemas na conservação e na digitalização ocorrem, principalmente, não por falta de informação, mas por falta de verba ou de tempo. Em qualquer âmbito, seja numa instituição, seja em coleções particulares, os problemas existem e são do conhecimento de todos.

A digitalização é uma necessidade reconhecida pelos profissionais e está presente nos manuais. Mesmo aqueles que, ao falarem em entrevistas ou ao publicarem sobre o tema, não a citem, têm predisposição para aceitá-la, já que ela beneficia a conservação dos suportes de som originais.

A tecnologia trouxe muitos benefícios desde o início da gravação sonora, mas as dificuldades criadas são problemáticas, principalmente no que diz respeito à integridade física dos suportes, já que existe um leque de composições em cada tipo, com diferentes velocidades de decomposição.

É necessário, portanto, criar uma conscientização coletiva quanto aos termos e às ações relacionadas à preservação de suportes e de documentos sonoros em geral. Isto é, planejamento, alocação de recursos e aplicação de métodos e tecnologias para assegurar que a informação digital permaneça acessível e utilizável (MÁRDERO ARELLANO, 2008).

O presente trabalho apontou impressões das recentes práticas de conservação, que trazem também antigos e bons costumes. É um trabalho muito nobre, que ainda tem muitos mistérios a serem desvendados. Deve-se explorar posteriormente a ação da acidez no papel, que destrói as capas protetoras dos suportes de som; e também verificar o que pode ser feito para recuperar suportes empenados ou quebrados. É válido também observar os termos legais e os benefícios que esses processos trarão às instituições e aos usuários.

As propostas de digitalização, por sua vez, são consequência de experiências recentes bem-sucedidas, mas ainda parecem distantes de um ideal que seja prático e permanente. Não é possível ter certeza acerca da funcionalidade da digitalização, saber se esta é a solução permanente ou se precisará ser refeita posteriormente. Talvez esta prática contenha métodos que, num futuro ainda distante, se mostrem prejudiciais para a conservação e a preservação dos suportes de som. 


\section{Referências}

COSTA E LIMA, C. Preservação Digital: a experiência da pesquisa Guignard. 2007. 100 f. Dissertação (Mestrado em Artes) - Escola de Belas Artes, Universidade Federal de Minas Gerais, Belo Horizonte, 2007.

ELP CORPORATION. ELP Laser Turntable. Japão, 2003. Disponível em: <http://www.elpj.com/>. Acesso em: 20 nov. 2009.

IASA Cataloguing Committee. The IASA cataloguing rules. 1999. Disponível em: <http://www.iasaweb.org/special_publications/cataloguing_rules/icat001.htm>. Acesso em: 10 out. 2009.

The safeguarding of the audio heritage: ethics, principles and preservation strategy, Version 3, 2005. Disponível em: <http://www.iasaweb.org/downloads/publications/TC03_English.pdf $>$. Acesso em: 10 out. 2009.

INNARELLI, H. C. Preservação de documentos digitais. 2007. In: SIMPÓSIO INTERNACIONAL DE BIBLIOTECAS DIGITAIS, 2., Campinas, 20 maio 2004. Campinas, 2004. Disponível em: <http://libdigi.unicamp.br/document/?down=8397>. Acesso em: 24 nov. 2009.

LAMURE, P. Thomas A. Edison. São Paulo: Cult Bras, 1935. 102 p.

MÁRDERO ARELLANO, M. A. Critérios para a preservação digital da informação científica. 2008. 354 f. Tese (Doutorado) - Universidade de Brasília, Departamento de Ciência da Informação, 2008. Disponível em: < http://hdl.handle. net/10482/1518>. Acesso em: 30 set. 2009.

MEY, E. S. A. Acesso aos registros sonoros: elementos necessários à representação bibliográfica de discos e fitas. 1999. 141 f. Tese (Doutorado) - Universidade de São Paulo, São Paulo, 1999.

PICCINO, E. Um breve histórico dos suportes sonoros analógicos. Revista Sonora. , v. 1, n. 2 p. 1-25, 2008.

SERRA, F. Áudio digital: a tecnologia aplicada à música e ao tratamento de som. Rio de Janeiro: Ciência Moderna, 2002. 137 p.

SIMEÃO, E. L. M. S.; MIRANDA, A. A conceituação de massa documental e - ciclo de interação entre tecnologia e o conhecimento registrado. Datagramazero, Rio de Janeiro, v. 3, n. 4, 2002. Disponível em: <http://www.dgz.org.br/out06/Art_03.htm>. Acesso em: 15 out. 2009.

ST. LAURENT, G. Guarda e manuseio de materiais de registro sonoro: conservação preventiva em bibliotecas e arquivos. 2. ed. Rio de Janeiro: Arquivo Nacional, 2001. (Projeto Conservação Preventiva em Bibliotecas e Arquivos, v. 43).

ORGANIZAÇÃO DAS NAÇÕES UNIDAS (UNESCO). Phonogrammarchiv; Austrian Academy of Sciences. Safeguarding Documentary Heritage: virtual exhibition. VIENNA, 2005. Disponível em: 
<http://www.unesco.org/webworld/virtual_exhibition/tapes2_2.shtml>. Acesso em: 20 nov. 2009. 